\title{
Entanglement network of agarose in various solvents
}

\author{
Jun-ichi Horinaka, Ryosuke Yasuda and Toshikazu Takigawa \\ Polymer Journal (2011) 43, 1000-1002; doi:10.1038/pj.2011.98; published online 28 September 2011
}

Keywords: agarose; ionic liquid; molecular weight between entanglements; organic solvent; polysaccharide

\section{INTRODUCTION}

The molecular structure of polysaccharides has led to the belief that these polymers are stiff. The characteristic ratio $\left(C_{\infty}\right)$ for polysaccharides is rather high, although reported $C_{\infty}$ values are limited to typical polysaccharides such as cellulose ${ }^{1}$ and gellan. ${ }^{2}$ If we can prepare concentrated solutions of polysaccharides, we can determine the molecular weights between entanglements in the molten state $\left(M_{\mathrm{e}, \text { melt }}\right)$ for these polysaccharides, ${ }^{3-5}$ which reflects the chain properties, that is, the flexibility of the chain. Since the first report that cellulose has good solubility in ionic liquids, ${ }^{6}$ many studies have been conducted to determine the solution properties of polysaccharides at high concentrations. We prepared concentrated solutions of several kinds of polysaccharides in an ionic liquid 1-butyl-3-methylimidazolium chloride $(\mathrm{BmimCl})$ and carried out rheological measurements for the solutions to determine $M_{\mathrm{e} \text {,melt }}$ for the polysaccharides. ${ }^{7-9}$ The experiments yielded rather small values of $M_{\mathrm{e} \text {,melt }}$ for the polysaccharides;

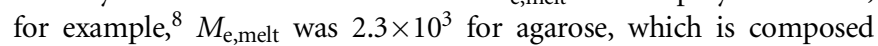
of $(1,3)-\beta$-D-galactopyranose and $(1,4)-3,6$-anhydro- $\alpha$-L-galactopyranose. ${ }^{10}$ This value appears to be much smaller than expected for a stiff polymer and is actually comparable to the $M_{\text {e,melt }}$ for the simplest flexible polymer polyethylene $\left(M_{\mathrm{e} \text {, melt }}=1.3 \times 10^{3}\right){ }^{3}$ although no reported value of $C_{\infty}$ for agarose is available. Why the $M_{e, \text { melt }}$ for polysaccharides is so small is not clear at present. The $M_{\mathrm{e}, \text { melt }}$ for amylose was also determined and was much larger than that for cellulose. ${ }^{7}$ To explain the $M_{\mathrm{e} \text {,melt }}$ values, it is necessary to examine whether the use of an ionic liquid as a solvent affects the estimation of $M_{\mathrm{e}, \mathrm{melt}}$. It has been proposed that ionic liquids form three-dimensional structures even in the liquid state because of cation-anion hydrogen bonding and cation-cation ring stacking. ${ }^{1-13}$ The threedimensional structure may contribute to the modulus of the solutions; if the elasticity due to the network of solvent molecules contributes to the plateau modulus $\left(G_{N}^{0}\right)$, then $M_{e, \text { melt }}$ is reduced. The aim of this study is to clarify whether or not the network formed by the ionic liquid molecules contributes to $G_{N}^{0}$. Concentrated solutions of agarose were prepared by using formamide (FA), $N$-methylformamide (MFA) and $\mathrm{BmimCl}$ as solvents. Angular frequency $(\omega)$ dependence curves of the storage and loss moduli ( $G^{\prime}$ and $G^{\prime \prime}$, respectively) were compared among these solutions.

\section{EXPERIMENTAL PROCEDURE}

Agarose (Research Organics, Cleveland, OH, USA) was used without further purification. FA (Wako, Osaka, Japan) and MFA (Aldrich, St Louis, MO, USA) were used as received. The ionic liquid BmimCl (Aldrich) was the same as that described in the previous studies. ${ }^{7,8}$ Agarose solutions were prepared as follows: agarose was added to each solvent (for $\mathrm{BmimCl}$, the solvent was preheated to convert it into the liquid state) in a dry glass vessel, and the mixture was quickly stirred with a stainless spatula on a hot plate at $\sim 80^{\circ} \mathrm{C}$. Then, the vessel was sealed and left on the hot plate for complete melting. The concentration of agarose (c) was $1.0 \times 10^{2}$ or $2.0 \times 10^{2} \mathrm{~kg} \mathrm{~m}^{-3}$, that is, ca 10 or $20 \mathrm{wt} \%$. In the calculation of c, $1.0 \times 10^{3} \mathrm{~kg} \mathrm{~m}^{-3}$ was assumed for the density of agarose, and $1.14 \times 10^{3}$, $1.00 \times 10^{3}$ and $1.08 \times 10^{3} \mathrm{~kg} \mathrm{~m}^{-3}$ were used for the densities of FA, ${ }^{14} \mathrm{MFA}^{14}$ and $\mathrm{BmimCl}, 7,8$ respectively. To minimize the effect of moisture absorption, a fresh bottle of solvent was used every time agarose samples were prepared, and the rheological measurements were made just after finishing the sample preparation.

Rheological measurements (dynamic viscoelasticity measurements in this study) were carried out with an ARES rheometer (now TA Instruments, New Castle, DE, USA) using the dynamic operation-testing mode under a nitrogen atmosphere. A cone-plate geometry with a diameter of $25 \mathrm{~mm}$ and a cone angle of $0.1 \mathrm{rad}$ was used. The $\omega$-dependence of $G^{\prime}$ and $G^{\prime \prime}$ for the solutions was measured with a strain amplitude $(\gamma)$ of 0.1 . Because the melting temperatures $\left(T_{\mathrm{m}}\right)$ of $\mathrm{FA}^{14}$ and $\mathrm{MFA}^{14}$ are reported to be 2.6 and $-5.4^{\circ} \mathrm{C}$, respectively, the temperature $(T)$ ranged from 5 to $40^{\circ} \mathrm{C}$ for the $\mathrm{FA}$ solution and from 0 to $30^{\circ} \mathrm{C}$ for the MFA solution. The T-range for the BmimCl solution was 20 $120^{\circ} \mathrm{C}$. For BmimCl, $T_{\mathrm{m}}$ is ca $70^{\circ} \mathrm{C}$, but the supercooled state of the $\mathrm{BmimCl}$ solutions was rather stable. Thus, viscoelasticity measurements were successfully taken even at $20^{\circ} \mathrm{C}$. The master curves in each solvent were prepared using only a horizontal shift with the shift factor $a_{\mathrm{T}}$.

\section{RESULTS AND DISCUSSION}

In Figure 1a the master curves of the $\omega$ dependence of the dynamic viscoelastic functions $\left(G^{\prime}\right.$ and $\left.G^{\prime \prime}\right)$ for the $\mathrm{BmimCl}$ and FA solutions of agarose at $c=100 \mathrm{~kg} \mathrm{~m}^{-3}$. The time-temperature superposition principle held very well for the $G^{\prime}$ and $G^{\prime \prime}$ curves for these solutions and for the other solutions examined in this study, as will be discussed below. The reference temperature $\left(T_{\mathrm{r}}\right)$ in the figure was set to $80^{\circ} \mathrm{C}$ for both solutions. For the FA solution, the dynamic viscoelasticity measurements were taken in the $T$-range of $5-20^{\circ} \mathrm{C}$. The master curves were prepared initially at $20^{\circ} \mathrm{C}$, and then the master curves were shifted so that $T_{\mathrm{r}}=80^{\circ} \mathrm{C}$ using the extrapolated values of $a_{\mathrm{T}}$. 
In the master curves for $\mathrm{BmimCl}$ solution ( $\mathrm{BmimCl}$ curves), the rubbery plateau and the terminal (flow) zones are clearly observed; the rubbery plateau is designated as the region of $G^{\prime}$ at $\log \omega a_{\mathrm{T}}$ of 2.2-4.7. Here, the plateau modulus $G_{N}^{0}$ can be defined as the $G^{\prime}$ value at $\omega a_{\mathrm{T}}$ where the loss tangent $\left(\tan \delta=G^{\prime \prime} / G^{\prime}\right)$ curve attains a minimum ${ }^{7-9,15}$ and is related to the molecular weight between entanglements $\left(M_{\mathrm{e}}\right)$ by

$$
G_{N}^{0}=\frac{c R T}{M_{\mathrm{e}}}
$$

where $R$ is the gas constant. It should be noted that $M_{\mathrm{e}}$ in the above equation should be in $\mathrm{kg} \mathrm{mol}^{-1}$. For the $\mathrm{BmimCl}$ solution at $c=100 \mathrm{~kg} \mathrm{~m}^{-3}$, we have a $G_{N}^{0}$ of $1.2 \times 10^{4} \mathrm{~Pa}$ for the $\mathrm{BmimCl}$ solution,
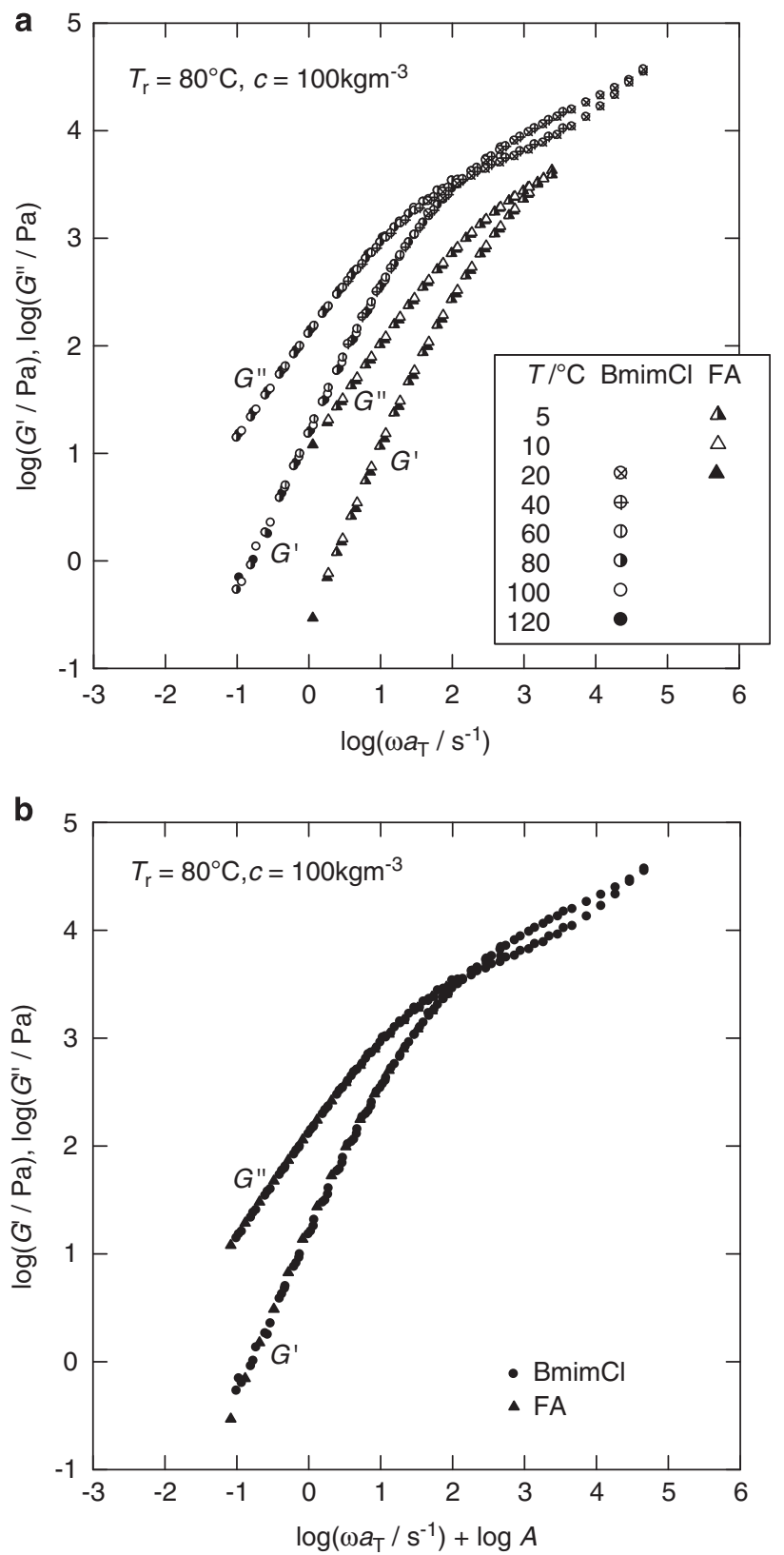

Figure 1 (a) Master curves of the $\omega$-dependence of $G^{\prime}$ and $G^{\prime \prime}$ for the 1-butyl-3-methylimidazolium chloride $(\mathrm{BmimCl})$ and formamide (FA) solutions of agarose at $c=100 \mathrm{~kg} \mathrm{~m}^{-3}$. The reference temperature, $T_{\mathrm{r}}$, is $80^{\circ} \mathrm{C}$. (b) The FA curves are horizontally shifted by the parameter $A$. which gives an $M_{\mathrm{e}}$ of $2.4 \times 10^{4}$. This value is consistent with the $M_{\mathrm{e}}$ values obtained in a previous study. ${ }^{8}$ In the master curves for the FA solution (FA curves), the flow zone is clearly observed. Concerning the rubbery plateau, however, only an onset of the plateau, that is, the intersection of the $G^{\prime}$ and $G^{\prime \prime}$ curves, emerges at the high $\omega a_{\mathrm{T}}$ limit, and the height of the intersection is identical to that on the $\mathrm{BmimCl}$ curves. Figure $1 \mathrm{~b}$ shows the same data as Figure 1a, but here the FA curves are horizontally shifted to have the best overlap with the BmimCl curves. The extent to which the curves were shifted is expressed by the parameter $A$, and $\log A=-1.14$ for the FA curves; for the BmimCl curves, $\log A$ is taken to be 0 . As can be seen from the figure, the horizontal shift was applied successfully. Our results suggest that the FA solution at $c=100 \mathrm{~kg} \mathrm{~m}^{-3}$ has the same number of entanglements as the $\mathrm{BmimCl}$ solution, although the high melting temperature of FA prevents measurements at low temperatures, and thus we were not able to obtain direct evidence of the dynamic viscoelasticity. The number (or more precisely, the number density) of entanglements appears to be independent of the solvent species as long as the solutions are homogeneous, as is well established for the synthetic polymers. Focusing on the properties of the ionic liquid $\mathrm{BmimCl}$, it is well known that $\mathrm{BmimCl}$ forms a three-dimensional structure, although the structure is not very strong. The lack of enhancement of $G_{N}^{0}$ in $\mathrm{BmimCl}$ compared with that in FA indicates that the lifetime of the $\mathrm{BmimCl}$ structure is sufficiently short, and therefore, the formation of the structure does not contribute to the modulus in the rubbery and terminal zones. In other words, $M_{\mathrm{e}}$ in the $\mathrm{BmimCl}$ solution depends purely on the chain-chain entanglements.

The parameter $A$ defined previously is related to the ratio of the zero-shear viscosity $\left(\eta_{0}\right)$ for the FA solution to that for the $\mathrm{BmimCl}$ solution, because $A$ is a type of horizontal shift factor and therefore has the same meaning as $a_{\mathrm{T}}$. Although we do not have detailed data on $\eta_{0}$, pure $\mathrm{BmimCl}$ and pure $\mathrm{FA}$ are expected to have very different $\eta_{0}$ values. However, at $c=100 \mathrm{~kg} \mathrm{~m}^{-3}$, the difference becomes rather small, only approximately one order of magnitude, because $\log A=-1.14$.

The plots of $a_{\mathrm{T}}$ versus $T^{-1}$ for the BmimCl and FA solutions of agarose at $c=100 \mathrm{~kg} \mathrm{~m}^{-3}$ are shown in Figure 2. It should be noted that $a_{\mathrm{T}}$ here is the shift factor from $T_{\mathrm{r}}\left(80^{\circ} \mathrm{C}\right)$ even for the $\mathrm{FA}$ solutions; namely, the original shift factor was modified so that at

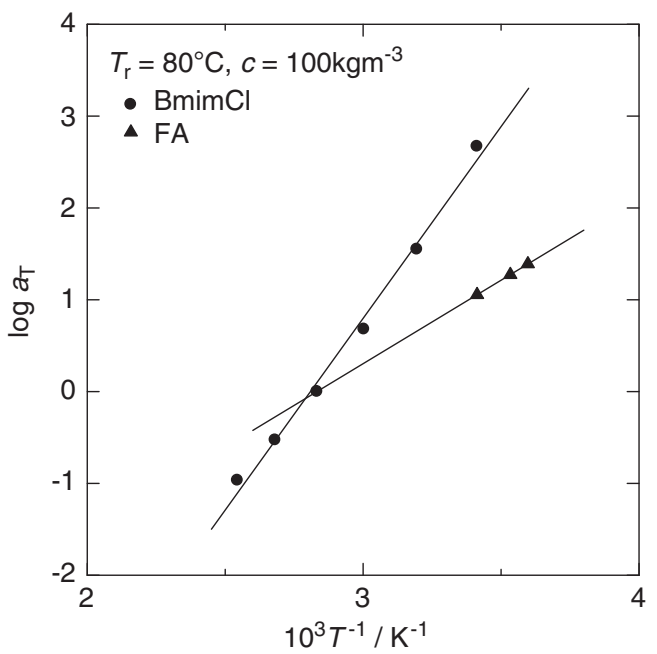

Figure 2 Shift factor at plotted against $T^{-1}$ for the 1-butyl-3methylimidazolium chloride $(\mathrm{BmimCl})$ and formamide (FA) solutions of agarose at $c=100 \mathrm{~kg} \mathrm{~m}^{-3}$. The reference temperature, $T_{\mathrm{r}}$, is $80^{\circ} \mathrm{C}$. 


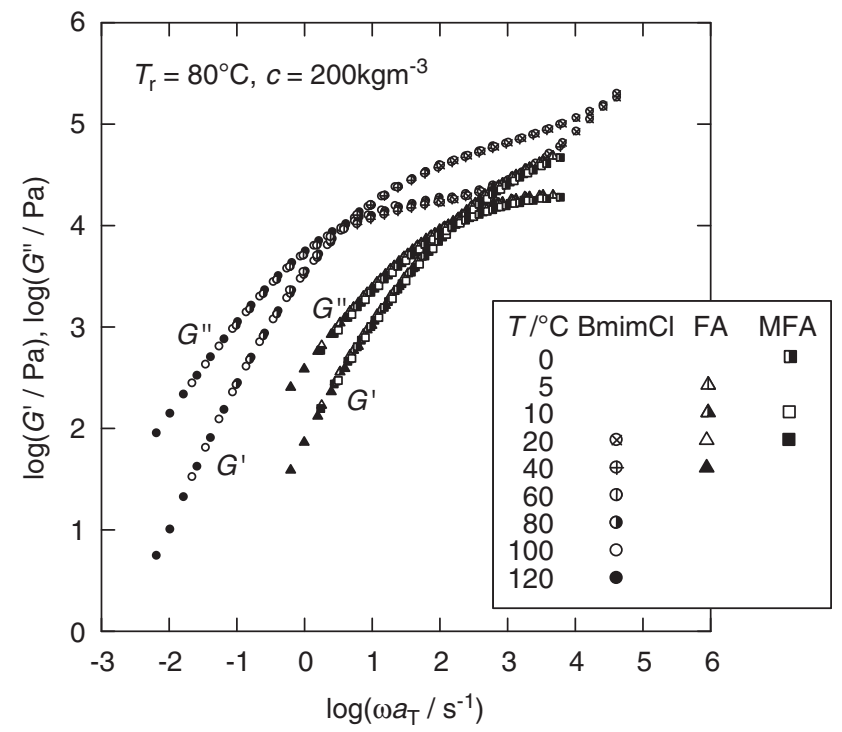

Figure 3 Master curves of the $\omega$-dependence of $G^{\prime}$ and $G^{\prime \prime}$ for the 1-butyl3-methylimidazolium chloride (BmimCl), formamide (FA) and $\mathrm{N}$-methylformamide (MFA) solutions of agarose at $c=200 \mathrm{~kg} \mathrm{~m}^{-3}$. The reference temperature, $T_{r}$, is $80^{\circ} \mathrm{C}$.

$80^{\circ} \mathrm{C} \log a_{\mathrm{T}}=0$. The data points for the FA solution fall on a single line, indicating that the T-dependence of $a_{\mathrm{T}}$ can be well described by an Arrhenius-type equation. The plots of $\log a_{\mathrm{T}}$ versus $T^{-1}$ for the $\mathrm{BmimCl}$ solution can also be approximated by a single line.

Figure 3 shows the master curves of $G^{\prime}$ and $G^{\prime \prime}$ of agarose in $\mathrm{BmimCl}, \mathrm{FA}$ and MFA at $c=200 \mathrm{~kg} \mathrm{~m}^{-3}$. The master curves for $\mathrm{BmimCl}$ cover a wide range of $\omega a_{\mathrm{T}}$ compared with the others because of the wider $T$-range of the measurements. For the plateau zone, we have a $G_{N}^{0}$ of $5.2 \times 10^{4} \mathrm{~Pa}$, leading to an $M_{\mathrm{e}}$ of $1.1 \times 10^{4}$ at $c=200 \mathrm{~kg} \mathrm{~m}^{-3}$. This $M_{\mathrm{e}}$ value is roughly half of that $\left(2.4 \times 10^{4}\right)$ for the solution at $c=100 \mathrm{~kg} \mathrm{~m}^{-3}$. The master curves for the FA and MFA solutions (FA and MFA curves, respectively) overlapped well with each other, and the flow zone and the onset of the plateau zone are observed for these curves, as in the case of the FA curves at $c=100 \mathrm{~kg} \mathrm{~m}^{-3}$. In addition, the intersections of $G^{\prime}$ and $G^{\prime \prime}$ for the FA and MFA curves are identical in height to that of the $\mathrm{BmimCl}$ curve, suggesting that $G_{N}^{0}$ is the same for these solutions, and therefore, it is expected that all three solutions will have the same value of $M_{\mathrm{e}}$. Again, $M_{\mathrm{e}}$ is independent of the solvent species.

The plots of $a_{\mathrm{T}}$ versus $T^{-1}$ are shown in Figure 4. Here, $a_{\mathrm{T}}$ is the shift factor from $T_{\mathrm{r}}\left(80^{\circ} \mathrm{C}\right)$ for all solutions; namely, the original shift factor was modified so that at $80^{\circ} \mathrm{C}, \log a_{\mathrm{T}}=0$ for the $\mathrm{FA}$ and MFA solutions. It is interesting that the data points for the FA and MFA solutions fall on a single line, indicating that the $T$-dependence of $a_{\mathrm{T}}$ can be well described by the same Arrhenius-type equation.

\section{CONCLUSION}

The rheological properties of concentrated solutions of agarose having two different concentrations were compared. Two organic solvents FA and MFA, and an ionic liquid $\mathrm{BmimCl}$ were used as the solvents. The $\omega$-dependence curves of $G^{\prime}$ and $G^{\prime \prime}$ for these solvents overlapped well only after a horizontal shift was introduced. The good agreement in the curves indicates that the entanglement properties of

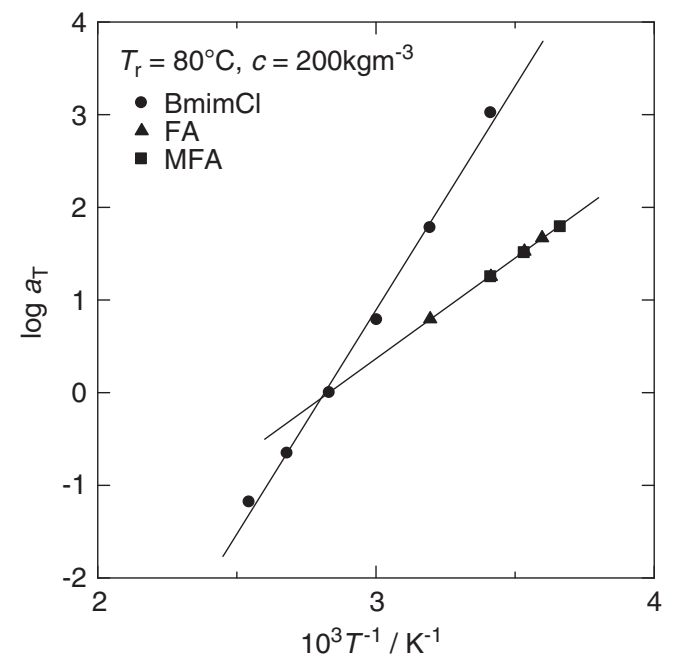

Figure 4 Shift factor $a_{T}$ plotted against $T^{-1}$ for the 1-butyl-3methylimidazolium chloride (BmimCl), formamide (FA) and $\mathrm{N}$ methylformamide (MFA) solutions of agarose at $c=200 \mathrm{~kg} \mathrm{~m}^{-3}$. The reference temperature, $T_{\mathrm{r}}$, is $80^{\circ} \mathrm{C}$.

the agarose chains are similar regardless of the solvent. The small $M_{e, \text { melt }}$ for polysaccharides can be attributed to the network of polysaccharide chains, not to the network formed by the ionic liquid molecules.

\section{CONFLICT OF INTEREST}

The authors declare no conflict of interest.

1 Cai, J., Liu, Y. \& Zhang, L. Dilute solution properties of cellulose in LiOH/urea aqueous system. J. Polym. Sci. B Polym. Phys. 44, 3093-3101 (2006).

2 Talashek, T. A. \& Brant, D. A. The influence of sidechains on the calculated dimensions on three related bacterial polysaccharides. Carbohydr. Res. 160, 303-316 (1987).

3 Ferry, J. D. Viscoelastic Properties of Polymers 366-403 (John Wiley \& Sons, New York, 1980).

4 Doi, M. \& Edwards, S. F. The Theory of Polymer Dynamics 218-288 (Clarendon, Oxford, 1986).

5 Onogi, S., Masuda, T. \& Kitagawa, K. Rheological properties of anionic polystyrenes. I. dynamic viscoelasticity of narrow-distribution polystyrenes. Macromolecules 3, 109-116 (1970)

6 Swatloski, R. P., Spear, S. K., Holbrey, J. D. \& Rogers, R. D. Dissolution of cellulose with ionic liquids. J. Am. Chem. Soc. 124, 4974-4975 (2002).

7 Horinaka, J., Yasuda, R. \& Takigawa, T. Entanglement properties of cellulose and amylose in an ionic liquid. J. Polym. Sci. B Polym. Phys. 49, 961-965 (2011).

8 Horinaka, J., Yasuda, R. \& Takigawa, T. Rheological properties of concentrated solutions of agarose in ionic liquid. J. Appl. Polym. Sci. (in press).

9 Horinaka, J., Honda, S. \& Takigawa, T. Rheological properties of concentrated solutions of gellan in an ionic liquid. Carbohydr. Polym. 78, 576-580 (2009).

10 Harris, P. Food Gels (Elsevier Applied Science, New York, 1990).

11 Hayashi, S., Ozawa, R. \& Hamaguchi, H. Raman spectra, crystal polymorphism, and structure of a prototype ionic-liquid [bmim]Cl. Chem. Lett. 32, 498-499 (2003).

12 Consorti, C. S., Suarez, P. A. Z., de Souza, R. F., Burrow, R. A., Farrar, D. H., Lough, A. J., Loh, W., da Silva, L. H. M. \& Dupont, J. Identification of 1,3-dialkylimidazolium salt supramolecular aggregates in solution. J. Phys. Chem. B 109, 4341-4349 (2005).

13 de Andrade, J., Boes, E. S. \& Stassen, H. Liquid-phase structure of dialkylimidazolium ionic liquids from computer simulations. J. Phys. Chem. B 112, 8966-8974 (2008).

14 O'Neil, M. J., Smith, A. \& Heckelman, P. E. (eds). The Merck Index (Merck \& Co., Inc., New Jergey, 2001).

$15 \mathrm{Wu}, \mathrm{S}$. Entanglement, friction, and free volume between dissimilar chains in compatible polymer blends. J. Polym. Sci. B Polym. Phys. 25, 2511-2529 (1987). 